\title{
Moderation in all things
}

If only St. Benedict were alive today. His saintly imprimatur would make life so much easier for those who want to take care of themselves without switching from one diet or exercise program to another like

\section{Omnia tamen mensurate fiant.}

\section{All things are to be done in moderation.}

\section{— The Rule of St. Benedict}

so many manic-depressives enduring troubling mood swings. The endless babble of conflicting and discouraging advice about what to eat and what to eschew in the name of perfecting a healthy mind and body is enough to make the strong of heart give up or give in.

During the fourth and fifth centuries of the common era, Western Christianity was practiced in monastic communities that existed on the fringes of society. Competing monastic groups tried to outdo cach other in strict asceticism, hoping to attract new converts with their version of the "no pain, no gain," school of religious thought.

Ours is an age of neoasceticism.

It is worth recalling that the best known of the written monastic rules - and the longest lived - is the Regula Sancti Benedicti, or the Rule of St. Bencdict, a codification of a lifestyle that attracted a large following by preaching moderation in all things. St. Benedict, it seems, knew what it means to be human, to balance pleasure and sacrifice. For example, he had sensible thoughts about food and drink long before food pyramids became fashionable. He recommended dinner at noon for those engaged in physical labor, and he took individual tastes into account, saying that two or three different dishes should be offered. St. Benedict favored a generous portion of bread and a hemina of wine a day (a quantity scholars still argue about). He cautioned against overindulgence and, intuitively grasping the connection between an optimistic mind and a healthy body, St. Benedict said that "above all clse" his monks should refrain from "grumbling."

How utterly refreshing. The ascetic Rulemakers of our time would do well to listen and to preach a message about diet and health that is simple to understand, simple to follow and, quite possibly, most likely to work: moderation in all things.

Instead, we labor for dietary perfection in a world with so many rules that obedience is nigh impossible. From scientific journals to popular magazines, from television news to the Internet, we are inundated with advice that reveals nothing so clearly as the fact that biomedical research is an everflowing stream, producing new data and new interpretations with unprecedented speed. Most food additives, such as salt, are harmful or harmless - Gepending. Vigorous exercise protects against cancer and the ravages of aging - maybe.

A random sampling of what has crossed our editorial desk in the past week is illuminating. The "Wellness Letter" from the University of California at Berkeley offers the following "wellness facts":

- Being obese increases the risk of developing cataracts.

- Goat meat, which has less than half the amount of fat than the leanest cuts of beef or pork, is the meat of the future.

- A cup of fresh carrot juice has as much beta carotene, vitamin $C$, and other vitamins as three medium carrots, but less fiber than a single carrot. (The putative protective effect of beta carotene as an anticancer agent was disputed by the most recent epidemiological data.)

Advice is also readily available from the activist Center for Science in the Public Interest, a Washington, DC-based group whose "Nutrition Action Healthletter" is now on the Internet, allowing its pearls of dietary wisdom to be downloaded by anyone, anywhere. What's in? Not Chinese or Mexican food, certainly. Italian, perhaps? You may be safe with spaghetti with tomato sauce, especially in Southern Italy where it is less likely to be contaminated by meat or cheese than in the North, where heart disease and cancer are more common. But even pasta and tomato sauce harbors a dark side - salt. In fact, most entrees "supply at least $1500 \mathrm{mg}$ of sodium," perilously close to the 1800 to $2400 \mathrm{mg}$ daily limit set by the salt police. According to the Center, there is something potentially harmful in every diet.

What's a body to do? Relax. Remember, it is now also part of the conventional wistom that anxiety is not only a disease, but a source of vulnerability to disease. Forget the conflicting pieces of evidence relating diet and disease until nutrition research matures, as it likely will during the coming decade or two. The Regula Sancti Benedicti has lasted 1500 years. The pronunciations of the neoascetics will not.

- Barbara J. Culliton 